\title{
Child Attributions Mediate Relationships Between Violence Exposure and Trauma Symptomatology
}

\author{
Kathryn S. Collins \\ Pamela A. Clarkson Freeman \\ George Jay Unick \\ Melissa H. Bellin \\ Polly Reinicker \\ Frederick H. Strieder
}

\begin{abstract}
Violence and trauma exposure have been increasingly investigated as contributing to a range of negative outcomes in child physical, cognitive, emotional, social, and psychological functioning, particularly among youth who are racial/ethnic minorities. This study presents findings related to children's attributions of their violence and trauma exposure. Attributions are inferences made about the cause of an event, situation, or action, with internal, stable, and global attributions most likely to lead to negative psychological outcomes. Data were drawn from an on-going clinical intervention study with families at risk for child maltreatment and/or neglect residing in a large metropolitan city on the East Coast. Mediation models provide evidence for a mediated relationship between violence exposure and PTSD through child attribution. Children develop their definitions of violence, formulate reasons why the violence occurs, and react to violence based on interpreting and developing cognitive attributions and schema about their experiences with violence in order to adaptively cope.
\end{abstract}

Keywords: Attributions; trauma; violence; PTSD; child therapy

Violence and trauma exposure continues to be an alarming public health concern and contributes to a wide range of negative outcomes for children. Violence and trauma exposure includes being a direct victim to, witnessing, or hearing about an actual or perceived threat of death, sexual violence, or injury (American Psychiatric Association [APA], 2013) as well as includes child neglect and abuse, community and family/intimate partner violence, natural and manmade disasters, accidents, and hospitalizations (GhoshIppen et al., 2002). The majority of children living in the United States will be exposed to violence directly (e.g., direct victim of violence, abuse, or trauma) or indirectly (e.g., witnessing or hearing about violent events from family or peers) at some point during their childhood, and recent data suggest nearly $60 \%$ of children were violence exposed in the previous 12-month period (Finkelhor, Turner, Shattuck, Hamby, \& Kracke, 2015). Research also suggests that children are more likely than adults to be exposed to violence at home, at school, or in the community (Finkelhor, Turner, Ormrod, Hamby, \& Kracke, 2009). Further, children from low-income urban neighborhoods are disproportionately

Kathryn S. Collins, MSW, PhD is an Associate Professor and Co-PI of the center for family informed trauma treatment at the University of Maryland School of Social Work. Pamela A. Clarkson Freeman, PhD, MSW, is a Research Assistant Professor, School of Social Work, University of Maryland. George Jay Unick, MA, MSW, PhD. is an Associate Professor, School of Social Work, University of Maryland. Melissa H. Bellin, PhD is an Associate Professor at the University of Maryland School of Social Work, Polly Reinicker, MSW, is a Research Assistant at the University of Maryland School of Social Work, Frederick H. Strieder, PhD, MSSA, is Clinical Associate Professor, School of Social Work, University of Maryland, Baltimore MD 21201. 
impacted since they are more likely to experience continuous exposure to traumatic events and violence in their home and community environment.

\section{Impact of Violence and Trauma on Children}

Exposure to violence can negatively impact and erode a child's physical, emotional, social, and psychological functioning. Violence exposure has been associated with numerous health risks including obesity, asthma, liver disease, heart disease and chronic obstructive pulmonary disease (Alves, Santos, Feitosa, \& Barreto, 2012; Centers for Disease Control (CDC), 2014; Mitchell et al., 2013; Sternthal, Jun, Earls, \& Wright, 2010). The Adverse Childhood Experience (ACE) Study assessed over 17,000 participants to examine the long-term effects of violence and trauma on biological, social, and psychological outcomes (CDC, 2014). The disturbing results suggest exposure to adverse childhood experiences often leads to depression, suicide attempts, alcohol abuse, sexual risk behaviors, illegal drug use, and unintended and early pregnancies (CDC, 2014). Other social effects of child exposure to trauma and violence include behavior problems in school, aggressive or criminal behavior, and setbacks in academic achievement (Busby, Lambert, \& Ialongo, 2013; Kliewer \& Sullivan, 2008; Salzinger, Feldman, Rosario, \& NgMak, 2010).

Children exposed to violence and trauma are also at increased risk for post-traumatic stress disorder (PTSD) which includes symptoms of unwanted, intrusive memories, avoidance of places, activities or talking about the event, emotional numbness and irritability, inability to maintain close relationships, guilt or shame, and inability to sleep or concentrate (American Psychological Association, 2017). Elevated rates of externalizing problems (anger, aggression and violence) and internalizing problems (anxiety, depression, and intrusive thoughts) are likewise found in youth who are exposed (Kelly, 2010; Salzinger et al., 2010). The deleterious impact of violence exposure on psychological symptoms is particularly pronounced among youth who are impoverished and are racial/ethnic minorities (Andrews et al., 2015).

\section{Risk and Protective Factors Associated with Trauma Outcomes}

While exposure to violence and victimization has the potential to cause harmful consequences, there are a variety of risk and protective factors that influence the effect of trauma on the individual child. Polyvictimization, which is the simultaneous exposure to violence across several domains (e.g., school, home, community), elevates risk for more severe child outcomes (Cyr, Clement, \& Chamberland, 2014; Finkelhor, Turner, Hamby, $\&$ Ormrod, 2011). Individual characteristics, such as the developmental and psychological levels of family processes (i.e. parent-child interactions), and the broader social context made up of neighborhoods, community resources, and social support are all proposed to shape a child's response to trauma (Belsky, 1993). Specific protective factors that seem to ameliorate the impact of violence and trauma exposure include child perceived safety, social and family support, family cohesion and stability, and ability to discuss the violent event in a safe space (Gorman-Smith, Henry, \& Tolan, 2004; Ozer \& Weinstein, 2004). 


\section{The Role of Attributions in Trauma Response}

The role of attributions that the child makes about the traumatic or violent experience is a fertile area of study in trauma science (Cohen \& Mannarino, 2002; Collins, Koeske, Russell \& Michalopoulos, 2013). Attribution theory suggests that the reason a child gives to the occurrence of a violent event or traumatic experience will impact his or her ability to cope with the event (Heider, 1958). Attributions are often characterized by the locus of control (internalizing versus externalizing), stability, and globality of the events. Internalizing attributions occur when people blame themselves for causing the event to happen, while externalizing attributions claim that the event was caused by factors outside of oneself (Kelley, 1973). Stability refers to whether the person views the cause of the event as constant or variable over time; such as saying that the event is inevitable (constant), versus attributing the cause of the event to be unstable (variable; Abramson, Seligman, \& Teasdale, 1978). Globality describes whether or not the event is generalizable to other aspects of life, or attributed to specific causes. A global explanation a person might make is "I am a bad person and nothing good will ever happen to me." The majority of the literature on attributions posits that internal, stable, and global attributions are most likely to lead to negative psychological outcomes regardless of trauma type (Deblinger \& Runyon, 2005; Knight \& Sullivan, 2006; Wenninger \& Ehlers, 1998).

Existing research suggests child attributions exert a significant influence on subsequent trauma symptomology (Collins et al., 2013; Knight \& Sullivan, 2006; Wenninger \& Ehlers, 1998; Zinzow \& Jackson, 2009). Both Collins et al. (2013) and Knight and Sullivan (2006) found that children who are low-income living in urban environments have higher levels of trauma symptomology and also report negative attributions such as self-blame, feeling different from peers, lack of trust in others, and lack of credibility. Similarly, adolescents who had negative threat appraisals (i.e. concerns about harm to others, harm to self, selfblame for violent events were more likely to report internalizing problems such as depression and anxiety (Collins et al, 2010; Kliewer \& Sullivan, 2008).

\section{Present Study}

The current study aimed to delineate the role of children's attributions of trauma on trauma symptomatology using a sample of children from a clinical intervention research protocol. Our main hypothesis is that both children's Direct Exposure (DE) and Indirect Exposure (IE) traumas and PTSD would be mediated by the children's attributions. However, consistent with the literature on negative attributions, we further hypothesized that the relationship between exposure to DE traumas and PTSD would be more strongly mediated by the attribution constructs compared with the IE traumas. Additionally, we expected each of the four attribution constructs (i.e., feeling different from peers due to their exposure, lack of perceived credibility [being believed] about their experience, lack of trust in others, and self-blame for the negative events or violence that occurred) to moderate the relationship between traumatic experiences and PTSD symptomatology. 


\section{Methods}

Data for the current study were drawn from families who are residing in extreme poverty and at risk for child maltreatment and/or neglect residing in a large metropolitan city on the East Coast who were referred for treatment and services because they were having difficulty meeting the basic needs of their families. To be eligible for services, families must have at least one child between the ages of 5 and 11 years old, and have.at least two child, family and/or caregiver risk conditions and one risk factor for child maltreatment or neglect. At the time of referral, families could not be involved in the child protection system, and the child had to reside with the custodial caregivers/guardians. Families are eligible for specialized trauma services if they have clinically significant scores on standardized measures for trauma symptomatology for caregiver and/or child. This includes caregivers with Post-Traumatic Checklist-Civilian (PCL-C; Weathers, Litz, Herman, Huska, \& Keane, 1993) scores greater than or equal to 50, children with UCLA PTSD index scores greater than or equal to 25, or children who met Criterion A (exposure to a traumatic event in which they felt threatened and responded with intense fear, helplessness, or horror) and any combination of criterions B (intrusive recollection), C (avoidance/numbing), or D (hyper-arousal) on the UCLA PTSD index (e.g., Criterion B and C, C and D, B and D)(Ruggiero, Ben, Scotti, \& Rabalais, 2003). Participants must also sign an informed consent and child assent to participate in the study.

\section{Sample}

A total of 259 out of 389 children screened for the trauma services program were deemed eligible (Figure 1). Eight families refused study participation resulting in a baseline sample of 251 families. Due to the decline in children with complete data (130/251), attrition analyses were conducted to examine systematic patterns of missingness. Independent-samples t-tests were conducted to determine any systematic patterns of missingness comparing the full sample of eligible children to the analytic sample. Children with missing data were slightly younger, $t(189)=2.14, p<.05$ ), and had higher average scores on two of the CAPS subscales: Feeling Different from Peers, $t(147)=-4.34, p<.01$; and Lack of Trust, $t(146)=-2.85, p<.01$ ) (Please see discussion on the CAPS instrument below). There were no other significant differences in socio-demographic characteristics or study constructs between the children with complete data versus those who were removed from the sample due to incomplete data. 
Figure 1. TA-FC Data Collection Diagram

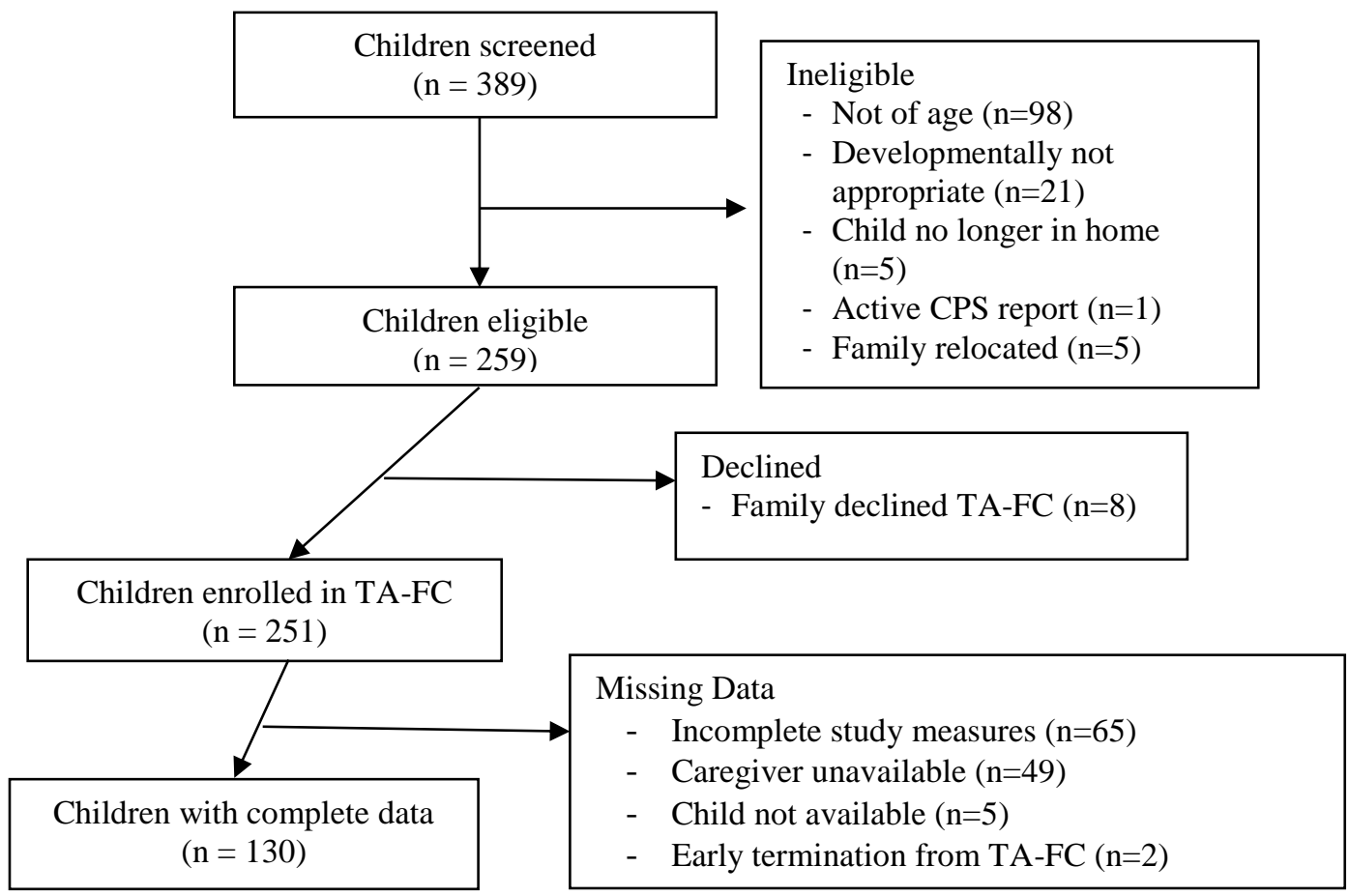

Demographic characteristics for the current sample are provided in Table 1. The sample was comprised of $54 \%$ males and $46 \%$ female. On average, children were 8.35 years $(S D=2.12)$, and the majority of children were African American/Black $(92.31 \%, n$ $=120)$.

Table 1. Child Demographic Characteristics

\begin{tabular}{lcc}
\hline & $n$ & $\%$ \\
\hline Gender & 70 & 53.85 \\
Male & 60 & 46.15 \\
Female & & \\
Race & 120 & 92.31 \\
$\quad$ African American/Black & 6 & 4.62 \\
Caucasian/White & 4 & 3.08 \\
$\quad$ Mixed Race & $M$ & $S D$ \\
\hline & 8.35 & 2.12 \\
\hline Child Age ( \pm SD; in months)
\end{tabular}

\section{Instruments}

Children's Attributions and Perceptions Scale (CAPS). The CAPS was created by Mannarino, Cohen, and Berman (1994) to assess children's attributions and interpretations after exposure to sexual abuse but is valid for use in children who have not experienced abuse. The scale contains four subscales which include eighteen total items. The four 
subscales measure "Feeling Different From Peers, Self Blame for Violence and Negative Events, Perceived Lack of Credibility, and Lack of Interpersonal Trust in Others" (Mannarino et al., 1994, p. 206). Internal consistencies range from $\alpha=.65$ to $\alpha=.73$ for the various subscales (Mannarino et al., 1994; current study $\alpha=.53$ to $\alpha=.85$ ). Children are given the scale in an interview format, and are asked to respond based on a Likert Scale from 1 (never) to 5 (always).

UCLA PTSD Symptom Scale - Child/Adolescent version. The UCLA PTSD Symptom Scale is taken from the UCLA PTSD Reaction Index developed based off of the criteria for PTSD in the DSM-IV-TR (Pynoos, Rodriguez, Steinberg, Stuber, \& Frederick, 1998). The symptom scale is comprised of 22 items that investigate reactions and feelings to a trauma that have occurred. Participants are asked to only evaluate their symptoms within the past month, and in the case of multiple traumas, are asked to evaluate their most severe or disturbing trauma. The frequency of symptoms is measured on a rating scale from 0 (None of the time) to 4 (Most of the time). The PTSD Reaction Index has high internal consistency ( $\alpha=90$; Steinberg \& Vivrette, 2013; current study $\alpha=.86$ ) and high test-retest reliability (.84; Steinberg et al., 2013).

Traumatic Events Screening Inventory (TESI-C). The 16-item TESI-C is used to screen for a child's history of exposure to potentially traumatic events. The instrument assesses whether the event was perceived as potentially life threatening and/or a risk for severe injury, and includes three probes that elicit the child's appraisal of the event. The TESI-C includes violent and/or potentially traumatic events towards both self and others, such as community and family/intimate partner violence, disasters, physical and sexual abuse, accidents, hospitalizations, and injuries (Ghosh-Ippen et al., 2002). The 16 items are broken into four groups of traumas: being sick or injured in an accident, being directly exposed to violence, witnessing domestic violence, and witnessing community violence. For this study we use only 11 of the 16 items to construct our two subscales: Direct Exposure (DE) if the trauma exposure was the result of being directly exposed to violence; or Indirect Exposure (IE) if they were the result of witnessing domestic violence or community violence. The DE subscale is comprised of five items such as "Has someone ever told you they were going to hurt you really badly, or acted like they were going to hurt you really badly?" IE is comprised of six items such as "Even if they weren't physically attacking each other, have you ever heard people in your family really yelling and screaming at each other a lot?"

\section{Data Analysis}

Means, standard deviations, frequencies and percentages were calculated for the UCLA PTSD Symptoms Scale, the four CAPS subscales, the overall TESI, and two interpersonal violence subscales (see Table 2). The main analytic approach was a set of moderation models, followed by mediation models, quantifying the role that the four CAPS attribution subscales have on the relationship between trauma exposure (e.g., DE and IE) and PTSD symptoms. 
Table 2. Summary of Means and Standard Deviations for Measures

\begin{tabular}{lcccc}
\hline & $M$ & $S D$ & Min & Max \\
\hline UCLA PTSD Overall Score & 28.0 & 19.83 & 0.0 & 83.0 \\
CAPS Feeling Different from Peers due to their & 8.73 & 4.06 & 0.0 & 20.0 \\
$\quad$ Exposure Subscale & & & & \\
$\quad$ CAPS Self Blame for Negative Events or & 7.28 & 3.66 & 0.0 & 18.0 \\
$\quad$ Violence that Occurred Subscale & & & & \\
CAPS Lack of Perceived Credibility Subscale & 13.47 & 4.60 & 0.0 & 25.0 \\
CAPS Lack of Trust in Others Subscale & 12.01 & 5.26 & 0.0 & 25.0 \\
$\quad$ TESI Scale - Total Traumatic Events & 4.50 & 3.60 & 0.0 & 15.0 \\
$\quad$ iirect Exposure Subscale & 1.04 & 1.27 & 0.0 & 5 \\
$\quad$ Indirect Exposure Subscale & 3.12 & 3.12 & 0.0 & 9 \\
\hline
\end{tabular}

The moderation models test for the effect that attribution has on changing the direction or strength of the relationship between the trauma and PTSD. Moderation is tested by interacting the attribution subscale with trauma exposure. We estimated eight moderation models (four for DE traumas and four for IE traumas) using Stata 14.1. The dependent variable for all eight moderation models was the UCLA PTSD Symptom Scale and all models adjusted for the age of the child. We estimated models for each of the four CAPS subscales, either DE and IE, and an interaction term of between attribution and trauma exposure as the key moderation variables. We also adjusted models for family clustering using cluster adjusted standard errors. The regression models also serve as tests of main effects between trauma exposure and attribution with the dependent PTSD variable.

In contrast to moderation, mediation models test whether the mediating variable (e.g., attribution) accounts for the relationship between the independent variable (e.g., trauma exposure) and dependent variable (e.g., PTSD). For the mediation analysis we used Stata 14.1 and the package sgmediation, which performs the regression calculations and conducts a Sobel-Goodman test of the mediator, and then used bootstrap estimation to calculate confidence intervals for the standard errors (Preacher \& Hayes, 2004). As with the moderation analysis, we estimated eight mediation models; each of the four subscales of the CAPS instrument were tested separately with the two different independent variables (DE and IE) and adjustments for child age and within family clustering. For each of the models the UCLA total PTSD scale score was used as the dependent variable. We also tested models that included sex and ethnicity, but they had no effect on either the moderation or mediation model coefficients (model results available on request).

The Stata user written command sgmediation uses three regression models to estimate the indirect and direct effects between the independent variable, the mediating variable and the dependent variable (see Figure 2). In the case of this analysis the first regression model estimated the association of the violence exposure (direct or indirect) with the UCLA PTSD scale (path c in Figure 2). The second model estimated the association of the DE or IE variables with one of the four attribution scales (path a in Figure 2). The final regression model estimated the association of both the Attribution scales and the violence exposure scales with the PTSD scale (path $b$ and $c$ from Figure 2). The program then estimates the joint effect of paths a and b, which is the indirect mediation effect, and the path c or direct effect of violence exposure on PTSD. We then used bootstrap resampling procedures to 
get a more robust estimate of the standard errors of the direct path (c path) and the (a and b) indirect paths. The use of the empirical bootstrap approach is particularly important for the indirect path, since it is not clear what the appropriate distribution for the joint $\mathrm{a}^{*} \mathrm{~b}$ coefficient is.

Figure 2. Attribution Mediating the relationship between DE and PTSD

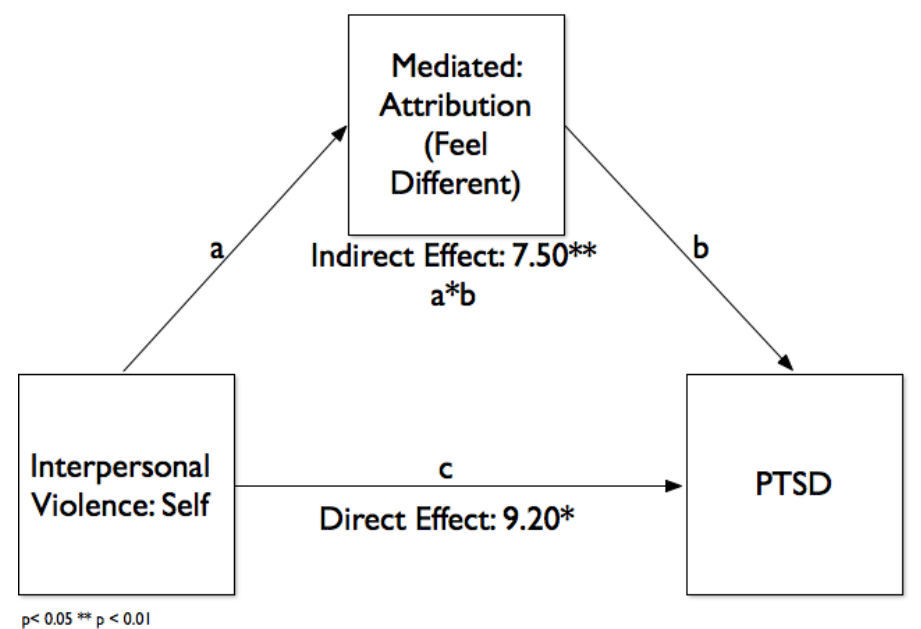

Results

Descriptive data for our measures are provided in Table 2, including means, standard deviations, and ranges. Overall raw scores on the UCLA PTSD can range from zero to 88. The average PTSD overall score was 28.0, $S D=19.83$, and there was a large range in symptomatology, with scores ranging from 0.0 to 83.0. The CAPS Feeling Different from Peers due to their Exposure subscale consists of 4 items, and scores can range from four to 20. The average score for the youth in our sample was $8.73, \mathrm{SD}=4.06$, and a wide range of scores was reported. The Self Blame for Negative Events or Violence that Occurred subscale also consists of four items. The average score for our sample was 7.28, $\mathrm{SD}=3.66$, with a range of scores from 4.0 to 18.0. The Lack of Perceived Credibility subscale includes five items, and scores can range from four to 25 . The average score of our sample was 13.47, $\mathrm{SD}=4.6$, with a full range of scores from four to 25. Lastly, the Lack of Trust in Others subscale contains five items. The average score for our sample was 12.01 ( $\mathrm{SD}=$ 5.26), with a range of scores from five to 25 . These averages are consistent with youth who have experienced trauma (Mannarino et al., 1994). On average, children reported being exposed to 4.5 different traumatic events, $S D=3.6$, with the number of exposures ranging from zero to 15 exposures.

Table 3 relays the results from eight moderation models that test the association between DE and IE, four attribution subscales, and PTSD as the dependent variables. The test for moderation effects is the interaction between the exposure to violence (DE and IE) and child attribution on child PTSD symptomotology. We did not find any evidence for an attribution moderated relationship between the effect of trauma (e.g., DE or IE) and PTSD in this sample of minority children who are low-income. Further, there is little evidence of 
a main effect relationship between exposure to trauma and PTSD and there is wide variation in the coefficients for violence exposure variables association with PTSD depending on which of the four attribution subscales were included. This wide variation in the violence exposure coefficients on PTSD and their wide confidence intervals suggests that after adjusting for children's attribution scores, there is little evidence for a main effect of exposure to violence to independently predict PTSD scores. The adjusted R2 value suggests that the combination of violence exposure variables, attribution variables and child age account for a relatively large $30 \%$ of the variance in PTSD.

Table 3. Moderation Models of Attribution and Violence Exposure on PTSD

\begin{tabular}{|c|c|c|c|c|c|c|c|}
\hline Attribution and DE on PTSD (UCLA) & Coefficient & SE & t & p-value & \multicolumn{2}{|c|}{$95 \% \mathrm{CI}$} & $\mathbf{R}^{2}$ \\
\hline $\mathrm{DE}$ & 6.84 & 13.89 & 0.49 & 0.62 & -20.83 & 34.50 & 0.26 \\
\hline Feel Different & 1.61 & 0.40 & 4.07 & $<.001$ & 0.82 & 2.39 & \\
\hline Interaction (DE by Different) & 0.25 & 1.09 & 0.23 & 0.82 & -1.91 & 2.41 & \\
\hline Child Age & 1.12 & 0.59 & 1.88 & 0.06 & -0.06 & 2.30 & \\
\hline Intercept & 4.84 & 6.65 & 0.73 & 0.47 & -8.41 & 18.08 & \\
\hline $\mathrm{DE}$ & 1.95 & 12.83 & 0.15 & 0.88 & -23.59 & 27.49 & 0.28 \\
\hline Self Blame & 1.90 & 0.53 & 3.59 & $<.001$ & 0.84 & 2.95 & \\
\hline Interaction (DE by Self Blame) & 0.36 & 1.19 & 0.30 & 0.76 & -2.01 & 2.73 & \\
\hline Child Age & 1.16 & 0.57 & 2.05 & 0.04 & 0.03 & 2.28 & \\
\hline Intercept & 5.66 & 6.25 & 0.90 & 0.37 & -6.80 & 18.11 & \\
\hline $\mathrm{DE}$ & -9.06 & 14.02 & -0.65 & 0.52 & -36.97 & 18.85 & 0.31 \\
\hline Lack Credibility & 1.33 & 0.40 & 3.30 & $<.001$ & 0.53 & 2.14 & \\
\hline Interaction (DE by Credibility) & 1.21 & 0.90 & 1.35 & 0.18 & -0.58 & 3.01 & \\
\hline Child Age & 0.89 & 0.55 & 1.62 & 0.11 & -0.21 & 1.98 & \\
\hline Intercept & 2.97 & 7.94 & 0.37 & 0.71 & -12.83 & 18.77 & \\
\hline $\mathrm{DE}$ & -4.81 & 12.52 & -0.38 & 0.70 & -29.75 & 20.13 & 0.32 \\
\hline Lack Trust & 1.15 & 0.32 & 3.59 & $<.001$ & 0.51 & 1.78 & \\
\hline Interaction (DE by Trust) & 1.12 & 0.77 & 1.45 & 0.15 & -0.42 & 2.66 & \\
\hline Child Age & 0.92 & 0.49 & 1.87 & 0.07 & -0.06 & 1.91 & \\
\hline Intercept & 6.64 & 6.34 & 1.05 & 0.30 & -5.99 & 19.27 & \\
\hline Attribution and IE on PTSD (UCLA) & Coefficient & SE & $\mathbf{t}$ & p-value & $95 \%$ & CI & $\mathbf{R}^{2}$ \\
\hline IE & 5.03 & 8.88 & 0.57 & 0.57 & -12.65 & 22.72 & 0.29 \\
\hline Feeling Different from Peers & 1.33 & 0.60 & 2.22 & 0.03 & 0.14 & 2.52 & \\
\hline Interaction (Other by Different) & 0.61 & 0.88 & 0.69 & 0.49 & -1.15 & 2.36 & \\
\hline Child Age & 0.70 & 0.65 & 1.08 & 0.28 & -0.59 & 1.99 & \\
\hline Intercept & 7.25 & 7.00 & 1.04 & 0.30 & -6.69 & 21.19 & \\
\hline IE & 23.25 & 8.06 & 2.89 & 0.01 & 7.21 & 39.30 & 0.32 \\
\hline Self Blame & 3.17 & 0.87 & 3.63 & $<.001$ & 1.43 & 4.91 & \\
\hline Interaction (IE by Self Blame) & -1.98 & 1.09 & -1.81 & 0.07 & -4.16 & 0.20 & \\
\hline Child Age & 0.58 & 0.63 & 0.92 & 0.36 & -0.68 & 1.84 & \\
\hline Intercept & -1.49 & 7.85 & -0.19 & 0.85 & -17.13 & 14.15 & \\
\hline IE & 6.68 & 11.94 & 0.56 & 0.58 & -17.09 & 30.45 & 0.32 \\
\hline Lack Credibility & 1.42 & 0.68 & 2.08 & 0.04 & 0.06 & 2.78 & \\
\hline Interaction (IE by Credibility) & 0.29 & 0.90 & 0.33 & 0.74 & -1.49 & 2.08 & \\
\hline Child Age & 0.53 & 0.58 & 0.92 & 0.36 & -0.62 & 1.69 & \\
\hline Intercept & 1.06 & 9.36 & 0.11 & 0.91 & -17.59 & 19.70 & \\
\hline IE & 17.88 & 8.68 & 2.06 & 0.04 & 0.60 & 35.16 & 0.32 \\
\hline Lack Trust & 1.77 & 0.53 & 3.33 & $<.001$ & 0.71 & 2.82 & \\
\hline Interaction (IE by Trust) & -0.69 & 0.74 & -0.94 & 0.35 & -2.16 & 0.77 & \\
\hline Child Age & 0.33 & 0.54 & 0.62 & 0.54 & -0.74 & 1.40 & \\
\hline Intercept & 1.73 & 6.64 & 0.26 & 0.79 & -11.50 & 14.96 & \\
\hline
\end{tabular}


Table 4 shows the results from the eight mediation models. In general, these models provide evidence for a mediated relationship between violence exposure and PTSD through child attribution. For each of the violence exposure variables (DE and IE) three of the four subscales of the CAPS had a statistically significant mediating effect on PTSD with only children's lack of trust in others not being significant at the $p<0.05$ level. Figure 2 presents the first regression displayed in Table 4. The indirect path though the mediator (Children Feeling Different from their Peers) accounts for $43.10 \%$ of the total variance in the relationship between DE and PTSD. These findings of a mediated relationship, provide support for the hypothesis that children's attributions about their violence and trauma exposure impact their risk of developing PTSD.

Table 4. Indirect and Direct Mediation Effects

\begin{tabular}{|c|c|c|c|c|c|c|c|c|c|}
\hline & IE & $(\mathbf{S E})$ & z-score & p-value & DE & (SE) & z-score & p-value & $\%$ Mediated \\
\hline \multicolumn{10}{|c|}{ DE to Violence regressed on PTSD (UCLA) } \\
\hline Feel Different from Peers & 7.12 & 2.62 & 2.72 & 0.007 & 9.40 & 4.87 & 1.93 & 0.053 & $43.10 \%$ \\
\hline Self Blame & 11.17 & 3.12 & 3.58 & $<0.001$ & 5.34 & 5.21 & 1.03 & 0.305 & $67.65 \%$ \\
\hline Lack Credibility & 6.98 & 2.83 & 2.47 & 0.014 & 9.53 & 4.68 & 2.03 & 0.042 & $42.29 \%$ \\
\hline Lack Trust in Others & 5.52 & 2.96 & 1.86 & 0.062 & 11.00 & 4.84 & 2.27 & 0.023 & $33.41 \%$ \\
\hline \multicolumn{10}{|c|}{ IE to Violence regressed on PTSD (UCLA) } \\
\hline Feel Different from Peers & 5.04 & 2.08 & 2.09 & 0.016 & 10.50 & 3.60 & 2.91 & 0.004 & $32.44 \%$ \\
\hline Self Blame & 5.84 & 2.10 & 2.23 & 0.009 & 9.70 & 3.70 & 2.62 & 0.009 & $37.57 \%$ \\
\hline Lack Credibility & 4.92 & 1.98 & 2.18 & 0.024 & 10.62 & 3.05 & 3.48 & 0.001 & $31.66 \%$ \\
\hline Lack Trust in Others & 5.71 & 2.38 & 2.32 & 0.014 & 9.83 & 3.42 & 2.87 & 0.004 & $36.74 \%$ \\
\hline
\end{tabular}

As a further check on our hypothesis we believed that DE to violence and trauma would be more strongly mediated by attributions than children's IE. For three of the four CAPS subscales the relationship between the DE variable had a higher percent of total effect for a given the CAPS subscale, i.e. the mediating variables. Only children's Lack of Trust in others had a stronger mediating effect on IE variable compared with the DE variable ( $33.41 \%$ vs $36.74 \%$, respectively). This provides some confirmatory evidence that the identified mediated relationship is consistent with the literature on risk of developing PTSD associated with internalizing and externalizing attributions.

\section{Discussion and Practice Implications}

As indicated in the Core Curriculum on Childhood Trauma (National Child Traumatic Stress Network [NCTSN], 2012), traumatic experiences are inherently complex. Children, adolescents and their families who are exposed to trauma experience subjective reactions to traumatic events that include changes in feelings, thoughts, and physiological responses, identity, relationship changes, and concerns for the safety of others. Through the range of experiences and attributions expressed by the children in both the DE and IE groups, we noted differences in exposures and the impact on PTSD. Garbarino (1995) stated that the most crucial feature of child development is the child's emerging capacity to form and maintain social maps. He suggested that social maps represent the world, reflect the simple cognitive competence of the child, and indicate the child's affective inclinations. Children's social maps include experiences in the larger environment in counterpoint with the child's 
inner life, both rational cognitive forces and the unconscious impetus. In our study, the social and internal maps of the children included feeling different from their peers because of their exposure, not being believed when they told their stories of exposure, having a great amount of self blame for violence and victimization as well as not trusting others in their environments. Our supported hypothesis that attributions mediate the relationship between exposure and PTSD at a great degree suggests the importance of continuing to create specific therapeutic strategies and tools aimed to help children learn about the impact of violence and trauma exposure via psychoeducation. Further, practitioners may consider methods to help the children deconstruct and rebuild the meanings they make about their experiences to challenge negative attributions, such as self blame.

As practitioners work with children and families affected by trauma, Briere and Scott (2006) suggest the following areas as a focusing psychoeducation on types of violence and trauma, myths associated with trauma including "blaming the victim", long and short term reactions to exposure and developing safety plans. Each of these areas may provide the children in both the DE and IE groups with accurate information to lessen the burden of exposure and begin reframing attributions.

Based on the data garnered from the children in this study and the research literature on the development of children's cognitive schema, our present study indicates that there are associations between levels of violence and trauma exposure and children's attributions. Children from the DE group expressed higher levels of problematic attributions about their exposure than the IE group. However, one cannot overlook that both groups were similar in their patterns of attributions as well as had the outcome of developing PTSD. Children in this study constructed their personal realities based on a learning process of being active participants in their environment. This is evidenced through the extent of specificity of children's attributions as they had higher frequencies and degrees of violence exposure. Simpson (1996) stated, "perceptions of safety and danger are 'intersubjective' products of social construction, collective agreement, and socialization" (p. 549). This suggests that although objective danger and violence exist, perceptions do not derive directly from observation of the empirical world. Instead, the objective environment provides only discrepant and ambiguous information about danger and violence, providing room for socially constructed beliefs.

Narrative therapy is one approach that may be beneficial to help children make meaning out their traumatic experiences and their social and emotional environments. This postmodernist approach is grounded in the concept that people's socially constructed interpretations of their life experiences and the meanings linked to these interpretations shape subsequent experiences. The goal is to help children reauthor and re-produce their life script, also known as a conversational map, according to alternative stories of identity. For example, a child with a history of repeated victimization might be encouraged to transform her life story, through telling and retelling, to one that emphasized themes of survivorship (White \& Epston, 1990). Duvall and Beres (2007) emphasizes, "Through the therapeutic conversation, this map provides a structure for therapists to introduce scaffolding to the person's story, helping him or her to move from the despair inherent in the knowable and taken-for-granted dominant story to the hope that is inherent in what is possible to know in the emergent alternate story" (p. 235). 


\section{Limitations}

Our study had limitations. Our data were collected at intake for services from families struggling to meet the basic needs of their children in one area of a large metropolitan city on the East Coast. The data, while providing informative results do not represent the general population. Our sample was also nearly 100 percent African American and not representative of other races or ethnicities. We did not analyze data from parents or teachers related to child outcomes and solely relied on the child's self report of their exposure, attributions and trauma symptomatology. Gaining information from a broader population with the inclusion of differing ages of children, parents, extended family members, teachers, and clergy, would be helpful contributions to the literature. We were concerned about the low alphas on a few of the subscales of the CAPS. We conducted a factor analysis that replicated the four factors of the developers to aid in establishing validity. Yet, the study would have benefited from a psychometrically stronger attribution measure. Finally, it is important to continue to use quantitative and qualitative research to study the mediators and moderators that promote and deter children's health and well-being as they are exposed to violence.

\section{Conclusion}

Overall, children in our society live, play, learn, and grow in a world where violence is pervasive. Children develop their definitions of violence, formulate reasons why the violence occurs, and react to violence based on interpreting and developing cognitive attributions and schema about their experiences with violence in order to cope, survive, and maintain resilience. It is important to continue to build these interventions to address negative and paralyzing attributions of children and reduce their trauma sympatomatology.

\section{References}

Abramson, L. Y., Seligman, M. E., \& Teasdale, J. D. (1978). Learned helplessness in humans: Critique and reformulation. Journal of Abnormal Psychology, 87(1), 49-72. doi: https://doi.org/10.1037/0021-843X.87.1.49

Alves, G. C., Santos, D. N., Feitosa, C. A., \& Barreto, M. L. (2012). Community violence and childhood asthma prevalence in peripheral neighborhoods in Salvador, Bahia State, Brazil. Cadernos de Saude Publica 28(1), 86-94. doi: https://doi.org/10.1590/S0102-311X2012000100009

American Psychiatric Association [APA]. (2013). Diagnostic and statistical manual of mental disorders: DSM-5. Washington, DC: Author.

American Psychological Association. (2017). Center for Epidemiological StudiesDepression. Retrieved from http://www.apa.org/pi/about/publications/caregivers/practicesettings/assessment/tools/depression-scale.aspx

Andrews, A. R., Jobe-Shield, L., Lopez, C. M., Metgzer, I. W., de Arellano, M. A., Saunders, B., \& Kilpatrick, D. G. (2015). Polyvictimization, income, and ethnic differences in trauma-related mental health during adolescence. Social Psychiatry 
and Psychiatric Epidemiology, 50(8), 1223-1234. doi:

https://doi.org/10.1007/s00127-015-1077-3

Belsky, J. (1993). Etiology of child maltreatment: A developmental ecological analysis. Psychological Bulletin, 114(3), 413-434. doi: https://doi.org/10.1037/0033$\underline{2909.114 .3 .413}$

Briere, J., \& Scott, C. ( 2006). Principles of trauma therapy: A guide to symptoms, evaluation, and treatment. Thousand Oaks, CA: SAGE

Busby, D. R., Lambert, S. F., \& Ialongo, N. S. (2013). Psychological symptoms linking exposure to community violence and academic functioning in African American adolescents. Journal of Youth and Adolescence, 42(2), 250-262. doi: https://doi.org/10.1007/s10964-012-9895-z

Centers for Disease Control and Prevention. (2014). Major findings. Retrieved from http://www.cdc.gov/violenceprevention/acestudy/findings.html

Cohen, J. A., \& Mannarino, A. P. (2002). Addressing attributions in treating abused children. Child Maltreatment, 7(1), 82-86. doi: https://doi.org/10.1177/1077559502007001008

Collins, K. S., Koeske, G. F., Russell, E. B., \& Michalopoulos, L. M. (2013). Children's attributions of community violence exposure and trauma symptomology. Journal of Child and Adolescent Trauma, 6, 201-216. doi: https://doi.org/10.1080/19361521.2013.811458

Collins, K.S., Connors, K., Davis, S., Donohue, A., Gardner, S., Goldblatt, E., Hayward, A., Kiser, L., Strieder, F. Thompson, E. (2010). Understanding the impact of trauma and urban poverty on family systems: Risks, resilience, and interventions. Baltimore, MD: Family Informed Trauma Treatment Center. Retrieved from http://nctsn.org/nccts/nav.do?pid=ctr_rsch_prod_ar

Cyr, K. C., Clement, M. E., \& Chamberland, C. (2014). Lifetime prevalence of multiple victimizations and its impact on children's mental health. Journal of Interpersonal Violence, 29(4), 616-634. doi: https://doi.org/10.1177/0886260513505220

Deblinger, E., \& Runyon, M. K. (2005). Understanding and treating feelings of shame in children who have experienced maltreatment. Child Maltreatment, 10, 364-376. doi: https://doi.org/10.1177/1077559505279306

Duvall, J., \& Béres, L. (2007). Movement of identities: A map for therapeutic conversations about trauma. In C. Brown \& T. Augusta-Scott (Eds.)., Narrative therapy: Making meaning, making lives (pp. 229-250). doi: http://dx.doi.org/10.4135/9781452225869.n12

Finkelhor, D., Turner, H., Hamby, S., \& Ormrod, R. (2011). Polyvictimization: Children's exposure to multiple types of violence, crime, and abuse. U.S. Department of Juvenile Justice Bulletin (October 2011). Retrieved from https://www.ncjrs.gov/pdffiles1/ojjdp/235504.pdf 
Finkelhor, D., Turner, H., Ormrod, R., Hamby, S., \& Kracke, K. (2009). Children's exposure to violence: A comprehensive national survey. U.S. Department of Justice Juvenile Justice Bulletin (October 2009). Retrieved from https://www.ncjrs.gov/pdffiles1/ojjdp/227744.pdf

Finkelhor, D., Turner, H., Shattuck, A., Hamby, S., \& Kracke, K. (2015). Children's exposure to violence, crime, and abuse: An update. U.S. Department of Justice Juvenile Justice Bulletin (September 2015). Retrieved from doi: http://www.ojjdp.gov/pubs/248547.pdf

Garbarino, J. (1995). The American war zone: what children can tell us about living with violence. Journal of Developmental \& Behavioral Pediatrics, 16(6), 431-435.

Ghosh-Ippen, C., Ford, J., Racusin, R., Acker, M., Bosquet, K., Rogers, C., \& Edwards, J. (2002). Trauma events screening inventory-parent report revised. San Francisco: The Child Trauma Research Project of the Early Trauma Network and The National Center for PTSD Dartmouth Child Trauma Research Group.

Gorman-Smith, D., Henry, D. B., \& Tolan, P. H. (2004). Exposure to community violence and violence perpetration: The protective effects of family functioning. Journal of Clinical Child and Adolescent Psychology, 33(3), 439-449. doi: https://doi.org/10.1207/s15374424jccp3303_2

Heider, F. (1958). The psychology of interpersonal relations. New York: Wiley doi: https://doi.org/10.1037/10628-000

Kelley, H. H. (1973). The processes of causal attribution. American Psychologist, 28(2), 107-128. doi: https://doi.org/10.1037/h0034225

Kelly, S. (2010). The psychological consequences to adolescents of exposure to gang violence in the community: An integrated review of the literature. Journal of Child and Adolescent Psychiatric Nursing, 23(2), 61-73. doi: https://doi.org/10.1111/j.1744-6171.2010.00225.x

Kliewer, W., \& Sullivan, T. N. (2008). Community violence exposure, threat appraisal, and adjustment in adolescents. Journal of Child and Adolescent Psychology, 37(4), 860-873. doi: https://doi.org/10.1080/15374410802359718

Knight, L. A., \& Sullivan, M. A. (2006). Preliminary development of a measure to assess children's trauma attributions. Journal of Aggression, Maltreatment \& Trauma, 13(2), 65-78. doi: http://dx.doi.org/10.1300/J146v13n02_05

Mannarino, A. P., Cohen, J. A., \& Berman, S. R. (1994). The Children's Attributions and Perceptions Scale: A new measure of sexual abuse-related factors. Journal of Clinical Child Psychology, 23(2), 204-211. doi: https://doi.org/10.1207/s15374424jccp2302_9

Mitchell, K. S., Aiello, A. E., Galea, S., Uddin, M., Wildman, D., \& Koenen, K. C. (2013). PTSD and obesity in the Detroit neighborhood health study. General Hospital Psychiatry, 35, 671-673. doi: https://doi.org/10.1016/j.genhosppsych.2013.07.015 
NCTSN Core Curriculum on Childhood Trauma Task Force. (2012). The 12 core concepts: Concepts for understanding traumatic stress responses in children and families. Core Curriculum on Childhood Trauma. Los Angeles, CA, and Durham, NC: UCLA-Duke University National Center for Child Traumatic Stress.

Ozer, E. J., \& Weinsten, R. S. (2004). Urban adolescents' exposure to community violence: The role of support, school safety, and social constraints in a sample of boys and girls. Journal of Clinical Child and Adolescent Psychology, 33(3), 463-476. doi: https://doi.org/10.1207/s15374424jecp3303_4

Preacher, K. J., \& Hayes, A. F. (2004). SPSS and SAS procedures for estimating indirect effects in simple mediation models. Behavior Research Methods, Instruments, \& Computers, 36(4), 717-731. doi: https://doi.org/10.3758/BF03206553

Pynoos, R., Rodriguez, N., Steinberg, A., Stuber, M., \& Frederick, C. (1998). The University of California at Los Angeles Posttraumatic Stress Disorder Reaction Index (UCLA-PTSD RI) for DSM-IV. Los Angeles, CA: UCLA Trauma Psychiatry Program.

Ruggiero, K. J., Ben, K. D., Scotti, J. R., \& Rabalais, A. E. (2003). Psychometric properties of the PTSD Checklist-Civilian version. Journal of Traumatic Stress, 16(5), 495-502. doi: https://doi.org/10.1023/A:1025714729117

Salzinger, S., Feldman, R. S., Rosario, M., \& Ng-Mak, D. S. (2010). Role of parent and peer relationships and individual characteristics in middle school children's behavioral outcomes in the face of community violence. Journal of Research on Adolescents, 21(2), 395-407. doi: https://doi.org/10.1111/j.1532-7795.2010.00677.x

Simpson, R. (1996). Neither clear nor present: The social construction of safety and danger. Sociological Forum, 11(3), 549-562. doi: https://doi.org/10.1007/BF02408392

Steinberg, A. M., Brymer, M. J., Kim, S., Briggs, E. C., Ghosh-Ippen, C., Ostrowski, S. A., Gully, K. J., \& Pynoos, R. S. (2013). Psychometric properties of the UCLA PTSD Reaction Index: Part 1. Journal of Traumatic Stress, 26, 1-9. doi: https://doi.org/10.1002/jts.21780

Steinberg, A. M., \& Vivrette, R. (2013). UCLA PTSD reaction index administration and scoring. Retrieved from: National Child Traumatic Stress Network http://www.nctsn.org/nctsn assets/pdfs/mediasite/ptsd-training.pdf

Sternthal, M. J., Jun, H. J., Earls, F., Wright, R. J. (2010). Community violence and urban childhood asthma: A multilevel analysis. European Respiratory Journal, 36(6), 1400-1409. doi: https://doi.org/10.1183/09031936.00003010

Weathers, F., Litz, B., Herman, D., Huska, J., \& Keane, T. (1993, November). The PTSD Checklist (PCL): Reliability, validity, and diagnostic utility. Poster session presented at the annual meeting of the International Society for Traumatic Studies, San Antonio, TX. 
Wenninger, K., \& Ehlers, A. (1998). Dysfunctional cognitions and adult psychological functioning in child sexual abuse survivors. Journal of Traumatic Stress, 11(2), 281300. doi: https://doi.org/10.1023/A:1024451103931

White, M., \& Epston, D. (1990). Narrative means to therapeutic ends. New York: WW Norton.

Zinzow, H. M., \& Jackson, J. L. (2009). Attributions for different types of traumatic events and post-traumatic stress among women. Journal of Aggression, Maltreatment \& Trauma, 18(5), 499-515. doi: https://doi.org/10.1080/10926770903051025

\section{Author note:}

Address correspondence to: Kathryn Collins, Department of Social Work, University of Maryland, 525 West Redwood Street, Baltimore, MD 21201, 410-706-0814, kcollins@ssw.umaryland.edu 